\title{
Acclimatized Apparatus Enhanced Seed Germination in Stevia rebaudiana Bertoni
}

\author{
Raji A. Abdullateef ${ }^{1,3}$, Mohamad bin Osman ${ }^{2} \&$ Zarina bint Zainuddin ${ }^{1}$ \\ ${ }^{1}$ Department of Biotechnology, Kulliyyah of Science, International Islamic University, Malaysia \\ ${ }^{2}$ Faculty of Plantation and Agrotechnology, UniversitiTeknologi MARA (UiTM), Shah Alam, Selangor, Malaysia \\ ${ }^{3}$ Sinwan Agricultural Research and Development Institute, Kwara State, Nigeria \\ Correspondence: Raji A. Abdullateef, Sinwan Agricultural Research and Development Institute, Ahli Sunnah close, \\ Gbagba, Airport road, Ilorin, Kwara State, Nigeria. Tel: 234-809-212-3099. Email: abdullateef_raji@yahoo.com
}

\author{
Received: October 29, 2014 Accepted: November 10, 2014 Online Published: January 26, 2015 \\ doi:10.5539/ijb.v7n2p28 URL: http://dx.doi.org/10.5539/ijb.v7n2p28
}

\begin{abstract}
Stevia rebaudiana bertoni produces sweet glycosides with zero calorie and has strong health and dietary implications. With these properties, it has the potential to substitute sugar. However, poor seed germination in this plant constitute obstacle towards large scale propagation, thereby causing plant materials to be scarce and costly. High percent seed germination could be induced via simulation of favorable climatic environment. Thus, new protocols and prototype tagged 'seed germination apparatus', inclusive of conducive factors, were developed. Additionally, Seed viability level was also tested using $1 \%$ tetrazolium chloride. ANOVA revealed significant differences between treatments at $p<0.05$. The apparatus influenced high yield of about $67 \%$ seed germination, while the viability test showed $69 \%$ viable seeds. Acclimatized condition, owing to innovated seed germination apparatus, showed high impact on seed germination in stevia.
\end{abstract}

Keywords: apparatus, climatic simulation, poor seed germination, prototype, sweet glycosides, stevia, zero calorie 1. Introduction

Stevia rebaudiana Bertoni, also known as sweet leaf, sugar leaf or "stevia", belongs to the family Asteracea and it is one of the 300 species of the genus. The species exist as herbs and shrubs (Soejarto, Compadre, Medon, Kamath, \& Kinghorn, 1983).

Stevia rebaudiana Bertoni is considered as a good substitute for sugar. It is a sweetener with zero calorie, indigestible in the human digestive tract because the compounds cannot be chemically breaking down. Thus, Stevia rebaudiana Bertoni constitutes a safe sweetener for diabetic patients (Strauss, 1995). The poor seed germination- 10\% (Sakaguchi \& Kan, 1992) and 36.3\% (Goettemoeller \& Ching, 1999) - problem with this plant caused obstacles towards establishment of Stevia rebaudiana Bertoni on a large-scale basis. This resulted in scarcity of the plant materials in terms of availability and cost effectiveness. Poor germination rates do not mean the seeds are dead. Non-germinability in seeds could be due to environmental factors such as very low humidity and extreme temperature (Murdoch \& Ellis, 2000) and endogenous factors. Where the germination percentage is low like in the case of Stevia rebaudiana Bertoni, carrying out both viability and germination tests on seeds become very essential, both tests will reveal the status of the seeds whether non-viable or dormant (Hidayati, J. Baskin, \& C. Baskin, 2002).

\subsection{Seed Germination}

Germination in seeds require necessary conditions which varies among plant depending on different species. Some of these conditions are stated below.

\subsubsection{Light}

The seeds of stevia are positively photoblastic (Brandle et al., 1998), thus, light is inevitable as a necessary factor for germinability.

Light plays important roles in plant development, as it is a necessary condition for photosynthesis to occur. Light also influences seed germination and seedling growth. In several plant species, light enhances seed germination, while in some plant species light inhibits seed germination (Jala, 2011). Different light treatments have been 
reported to affect seed germination of Nepenthes mirabilis (Jala, 2011). White and red light positively influenced germination in seeds, while the effect of red light is unparalleled.

In response to light, plants possess photoreceptors which include phytochrome, cryptochromes and one or more unrevealed ultraviolet light receptor(s), which are utilized for detecting and absorbing light (Runkle \& Heins, 2001). Phytochrome is protein in nature, and its absorbance value varies in respect of different wavelength of the light spectrum. Peak absorbance are in the red region of the wavelength, ranging from 600 to $700 \mathrm{~nm}$, and far-red region with wavelength ranging from 700 to $800 \mathrm{~nm}$, while the least absorbance is in the blue region with wavelength ranging from 400 to $500 \mathrm{~nm}$ (Runkle \& Heins, 2001).

\subsubsection{Photoperiod Extension}

Plant species respond to varying photoperiod for flowering and vegetative development. The use of extended light exposure periods, which varies from $8 \mathrm{~h}$ to $24 \mathrm{~h}$ length of day light was reported to show different impacts on seed germination in Rhododendron vaseyi, however overall germination at $30 / 20 \mathrm{C}(86 / 68 \mathrm{~F})$ with a $24-\mathrm{hr}$ photoperiod produced highest percentage of germinated seeds (LeBude et al., 2008, Walker et al., 2006).

\subsubsection{Temperature}

Optimum temperature for effective seed germination depends on plant species, in most cases optimal germination profiles are found at intermediate temperatures. From previous studies, a temperature regime of $25^{\circ} \mathrm{C}$ was found to be optimum in Stevia rebaudiana seed germination (Carneiro et al., 1992).

\subsubsection{Humidity}

Seeds need moist condition to germinate (Styer \& Koranski, 1997). The amount of water in the air determines its humidity. Optimum humidity is required for seeds to germinate, this is because at extreme low or high humidity, due to soil water content, poor seed germination may result.

\subsection{Seed Viability}

The most common and reliable method used for seed viability test is tetrazolium chloride (TTC) method (Traveset, 1998). TTC is accepted by the International Rules for Seed Testing (ISTA) as a chemical for testing seed viability (1999). This method has been effectively utilized across a wide range of plant species to predict germination and growth of seedling (Oliveira, Forni-Martins, Magalhães, \& Alves, 2004).

\subsection{Statement of the Problem}

Seed germination is very low making production of plant materials difficult and expensive.

Studying new approaches to enhance seed germination profile in stevia becomes essential since the poor seed germination problem remains unresolved, despite several research works.

\subsection{Aim of the Study}

The aim of the current study therefore, is to unravel new protocols and innovate a germination apparatus to simulate a conducive climatic conditions for high seed germination profile in Stevia rebaudiana Bertoni.

\section{Method}

\subsection{Seed Germination}

In this study, new protocols and apparatus were developed and investigated for efficacy on seed germination enhancement in Stevia rebaudiana Bertoni.

\subsubsection{Prototype: Seed Germination Apparatus}

The seed germination apparatus comprised of the following: (i) Planting tray where the seeds are germinated, (ii) peat moss, which served as the sowing medium, (iii) plastic dome to house the planting tray, (iv) light chamber affixed with two red fluorescent tubes to supply the light, (v) watering can for spraying water over the peat moss, (vi) timer switch to regulate period of light exposure, which was $7 \mathrm{am}$ to $9 \mathrm{pm}$, (vii) air conditioner, to regulate the temperature of the environment where the apparatus was set up. The whole apparatus was set up in the biological science laboratory of the kulliyyah of science.

\subsubsection{Protocols}

The protocols were developed to overcome poor seed germination in Stevia rebaudiana Bertoni, the details are explained below: 


\section{[i] Seed Harvesting, Storage Period and Sowing}

Seed was harvested on sunny days as the pappus were dried and easily detached from the parent plants by gentle shaking. Harvesting on wet weather may pose some stress and seeds may decay during storage. Stevia seeds are sown 3-5 days after harvest, but may be stored up to 14 days in a fridge before sowing. Under room temperature with proper ventilation, storage should not exceed one week. Otherwise the small endospermic source of food for the embryo is consumed and seed fertility becomes affected.

[ii] Seed sowing in planting tray

Peat moss was used as the planting medium, it was filled into the holes of a planting tray. There were twenty (Lee et al., 2002) holes per a planting tray, and three seeds were sown in the peat moss per hole, indicating total number of 60 seeds per tray. A sowing depth of $0.3-0.5 \mathrm{~cm}$ was maintained because light irradiation could easily reach the seeds. The planting tray was then transferred into a thick, transparent, plastic dome. Three replicates of the dome were placed in the light chamber $n$ under light irradiation.

[iii] Light

The plastic dome containing the planting tray was placed under red light irradiation (wavelength $660 \mathrm{~nm}$ ) in the light chamber. The distance between the affixed light tubes (36 watts) in the light chamber and the surface of the planting tray in the plastic dome is about $16 \mathrm{~cm}$. The light intensity value using data logger was at an average of $423 \pm 10$ lux. Red light gives better germination rate considering earlier findings (Raji \& Osman, 2011; Shyam \& David, 1975).

[iv] Extension of light exposure period

The period of light exposure of $14 \mathrm{~h}$ was maintained using a timer switch. Red light was switched on between 7.30 am to $9.30 \mathrm{pm}$ daily in the light chamber. This is because Stevia rebaudiana Bertoni is a short day plant (Brandle, Starratt, \& Gijzen, 2000). In addition, extension of light exposure period had shown positive impact on seed germination profile (LeBude et al., 2008, Walker et al., 2006).

[v] Temperature

Temperature was kept at $24^{\circ} \mathrm{C}$ using the air conditioner throughout the period of the experiment, based on previous work by Raji and Osman (2011), Sakaguchi and Kan (1992), following standard method (Goettemoeller \& Ching, 1999).

[vi] Humidity

Water was sprayed on the peat moss at 2 days interval. Since the planting tray was placed inside the plastic dome, the water loss was controlled, thereby assisting in maintaining the humidity of the environment at an average value $\mathrm{RH}=83.8 \pm 3.2 \%$, using data logger, throughout the experiment.

\subsubsection{Control Experiment}

A control experiment was set up as in section 2.1.2.2, except that the domes were placed under natural environmental conditions to observe the seed germination performance.

\subsection{Seed Viability}

Two hundred black Stevia rebaudiana Bertoni seeds were divided into four groups, each containing 50 seeds. Three groups (replicates) were treated with $1 \%(\mathrm{w} / \mathrm{v})$ Tetrazolium chloride (TTC) in schott bottles, prepared by dissolving $1 \mathrm{~g}$ of TTC in $100 \mathrm{ml}$ of distilled water (Traveset, 1998). For the control remaining one group of seeds was boiled in water inside a beaker placed on a Bunsen burner for five minutes in order to kill the seeds. Seeds were then transferred into a schott bottle containing TTC solution. All the samples were incubated at room temperature for $24 \mathrm{~h}$ in dark condition. After $24 \mathrm{~h}$, the seeds were removed from TTC solution and staged on a Carl Zeiss micro imaging dissecting microscope for embryo observation. Seeds were considered viable when 90-100 \% of the embryo surface was stained red with TTC (Oliveira et al., 2004; Bhering, Dias, \& Barros, 2005). Experiment was conducted three times and data were subjected to one-way analysis using paired sample ' $t$ ' test, with SPSS version 16.

\subsection{Statistics}

Data collected from experiments were analyzed using ANOVA with the SPSS version 16.

\section{Results}

\subsection{Seed Germination}

\subsubsection{Seed Germination Apparatus}

Seed germination rate and percentage were highly influenced under the controlled environmental conditions using the germination apparatus (Figure 1). 
The seed germination rate was 3.5 days (Figure 2), while the percentage of seed germination showed $67.33 \%$ (Figure 3) due to effects of the germination apparatus. However, the seed germination rate was 12 days (Figure 2), while the percentage of seed germination was $14 \%$ (Figure 3) considering the control experiment.

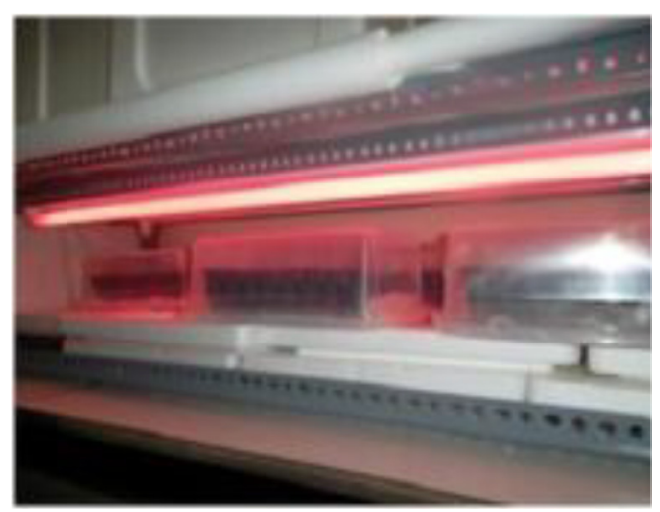

(a) Apparatus set up: seed tray in dome inside red light chamber.

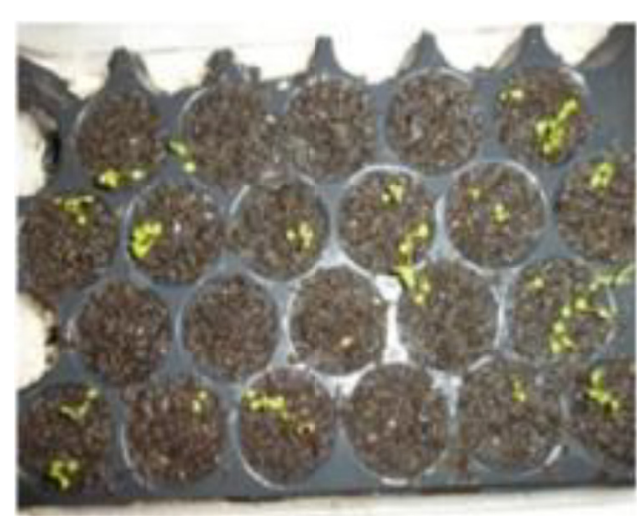

(b) Seedlings from germinated seeds in planting tray under controlled conditions.

Figure 1. Seed germination apparatus

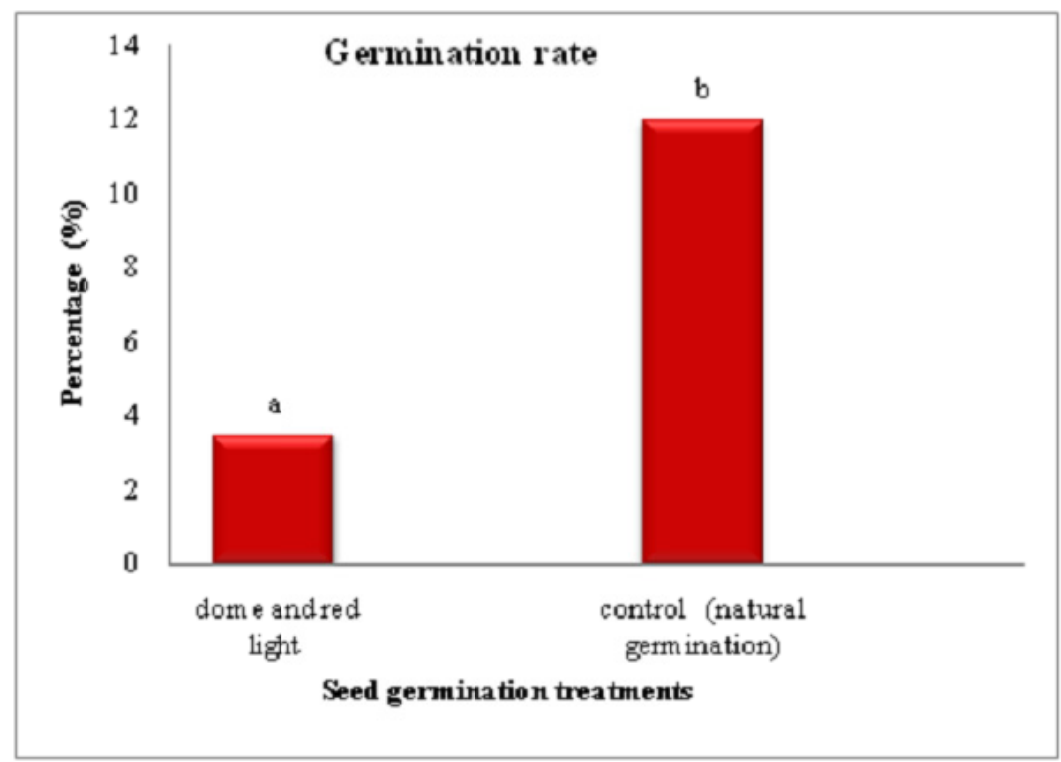

Figure 2. Effects of irradiation and box techniques on germination rate in seed of stevia. Different alphabets denote significant difference at $p<0.05$

In summary, the seed germination rate and percentage have been successfully improved in Stevia rebaudiana Bertoni through the innovation of the irradiated seed germination box and necessary protocols. The $67.33 \%$ of germinated seeds observed in this study showed better output over findings from earlier publications which reported $36.3 \%$ (Goettemoeller \& Ching, 1999) and 41\% (Raji \& Osman, 2011) for seed germination in stevia. The efficacy may be attributed to provision of suitable conditions for germination.

\subsection{Seed Viability}

The viability test showed that stevia seeds are viable. The embryo of viable seeds are stained uniformly red as shown in Figure 4. Results in Figure 5 showed that $68.67 \%$ of the seeds were viable while $31.33 \%$ were non-viable. The red colour of embryo was due to reduction of 2,3,5-triphenyl tetrazolium chloride in the presence of oxygen as a result of respiration occurring in the living cells of the embryo of viable seeds. The observed yellowish colour on other embryos was due to inability of the embryo to pick stain, possibly because it was dead. 


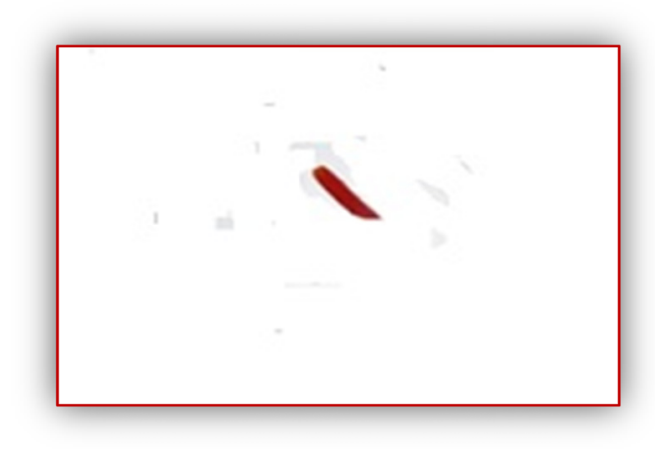

(a) : Viable seed embryo

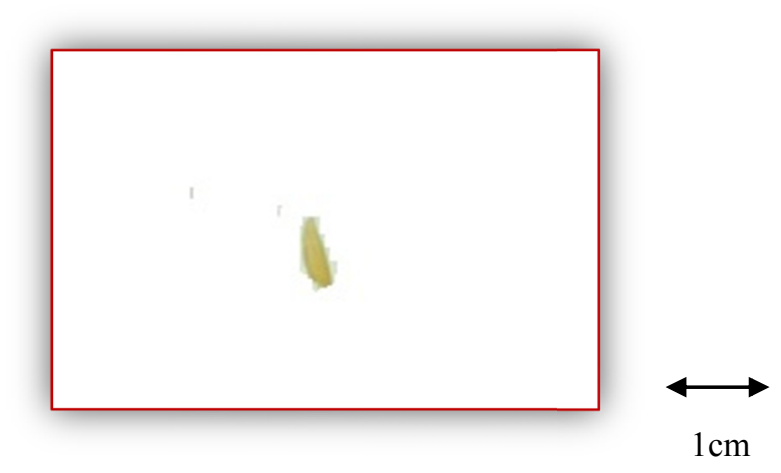

(b):Non-viable seed embryo

Figure 4. Seed Viability Tests With Tetrazolium Chloride (Ttc)

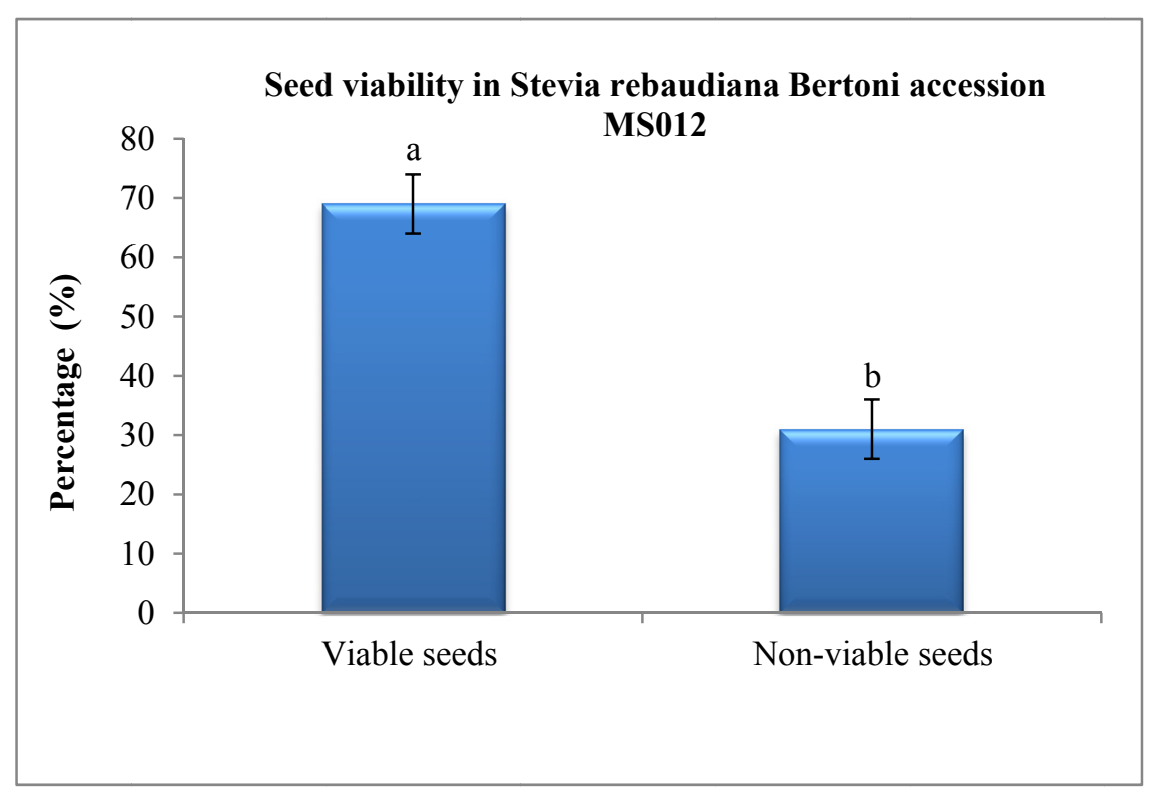

Figure 5. Percentage seed viability. Different alphabets denote significant difference at $p<0.05$.

\section{Discussion}

The influence of conducive environmental factors or conditions on seed germination and plant growth and development generally, cannot be over emphasized. In this study, environmental conditions such as light, light extension period, temperature and humidity were controlled for, using invented protocols and the germination apparatus. This approach yielded high level profile in seed germination of Stevia rebaudiana Bertoni, a plant species known for poor seed germination (Sakaguchi \& Kan, 1992).

The achievement of 3.5 days in rate of seed germination in Stevia rebaudiana Bertoni, as compared to 12 days in previous studies by Raji and Osman (2011), and 67.33\% in seed germination in comparison with $36.3 \%$ and $41 \%$ by Goettemoeller and Ching (1999) and Raji and Osman, (2011) respectively, showed the efficacy of the protocols and the apparatus.

Stevia rebaudiana is a short day plant (Brandle et al, 2000) and the seeds are positively photoblastic (Brandle et al., 1998 ) in nature, meaning therefore, that, exposure to light, and at the same time, the period of exposure, are two inevitable conditions for the seeds to germinate. The use of red light in particular, and the $14 \mathrm{~h}$ exposure of the seeds to light are in consonance with previous findings. Dry seeds contain a higher concentration of ABA than GA, thus inhibiting seed germination (Lee et al., 2002). However, the concentration of ABA decreases after water imbibitions, which allow germination to occur. Red light decreases ABA concentration and increased GA levels, this stimulates 
seed germination. Seeds of Nepenthes mirabilis germinated under red light showed the highest speed of emergence, compared to white, green, blue, and yellow lights (Jala, 2011). Similarly, the red light was utilized to increase the germination percentage of Merremia sp. (Seo et al., 2006) and Chromolaena odorata (Ambika, 2006). Furthermore, extension in period of light exposure of seeds in Rhododendron vaseyi species yielded high percentage germination (LeBude et al., 2008, Walker et al., 2006).

Seed germination is temperature dependent (Young et al., 2003) and also vary according to plant species. Sakaguchi and Kan (1992) found an optimum temperature range of $15-30^{\circ} \mathrm{C}$ to be effective for seed germination in Stevia rebaudiana Bertoni. The plastic dome serve to conserve water loss from the peat moss, thereby regulating moisture content and thus, the humidity in the environment within it. Seeds subjected to persistent optimum humidity therefore, stand good chance of high germination profile.

The fact that certain seeds have poor germination rates does not mean they are dead. Non-germinability in seeds could be due to environmental factors such as very low humidity and extreme temperature (Murdoch and Ellis, 2000). The most common and reliable method used for seed viability test is tetrazolium chloride (TTC) method (Traveset, 1998). TTC is accepted by the International Rules for Seed Testing (ISTA) as a chemical for testing seed viability (ISTA, 1999). Oliveira et al. (2004) stated that this method has been effectively utilized across wide range of plant species to predict germination and growth of seedling. The high percentage viability result in this study indicated that the stevia seeds are viable.

\section{Conclusion}

Stevia rebaudiana seeds are viable. The poor seed germination problem is actually due to inappropriate conditions of germination. Controlled environmental conditions highly improved seed germination in the crop.

\section{Acknowledgement}

Our appreciation goes to the research management center of the International Islamic University Malaysia (IIUM) for sponsoring this research through the endowment fund, 'EDW B 10-116-0455' JAZAKUMULLAHU KHAIRAH.

\section{References}

Abdullateef, R. A., \& Osman, M. B. (2011). Effects of Visible Light Wavelengths on Seed Germinability in Stevia rebaudiana Bertoni. International Journal of Biology, 3(4), 83.

Ambika, S. R. (2006). Effect of light quality and intensity on emergence, growth and reproduction in Chromolaena odorata. Proc. of the Seventh International Workshop on Biological Control and Management of Chromolaena odorata and Mikania micrantha, Taiwan (pp. 14-17).

Bhering, M. C., Dias, D. C. F. S., \& Barros, D. I. (2005). Adequação da metodologia do teste de tetrazólio para avaliação da qualidade fisiológica de sementes de melancia. Revista Brasileira de Sementes, 27(1), 176-182. http://dx.doi.org/10.1590/S0101-31222005000100022

Brandle, J. E., Starratt, A. N., \& Gijzen, M. (2000). Stevia rebaudiana. Its biological, chemical and agricultural properties. Agriculture and AgriFood Canada. Southern Crop Protection and Food Research Centre, 1391 Sandford St., London, Ontario N5V 4T3. Retrieved from www.lni.unipi.it/stevia/stevia/stevia0005.htm

Carneiro, J. W. P., \& Guedes, T. A. (1992).Influence of the contact of stevia seeds with the substrate, evaluated by means of the Wiebull function.Revista Brasileira de Sementes, 14(1), 65-68.

Goettemoeller, J., \& Ching, A. (1999). Seed germination in Stevia rebaudiana. p. 510-511. In: J. Janick (ed.), Perspectives on new crops and new uses. ASHS Press, Alexandria, VA. Retrieved from http://www.lni. unipi.it/stevia/stevia/v4-510.htm

Hidayati, S. N., Baskin J. M., \& Baskin C. C. (2002). Effects of dry storage on germination and survivorship of seeds of four Lonicera species (Caprifoliaceae). Seed Sci. Technol., 30, $137-148$.

Hsieh, W. P., Hsieh, H. L., \& Wu, S. H. (2012). Arabidopsis bZIP16 transcription factor integrates light and hormone signaling pathways to regulate early seedling development.Plant cell, 24(10), 3997-4011. http://dx.doi.org/10.1105/tpc.112.105478

International Seed Testing Association. (1999). Biochemical test for viability. Seed Sci. Technol., 27(supplement), 201-244.

Jala, A. (2011). Effects of Different Light Treatments on the Germination of Nepenthes mirabilis. International Transaction Journal of Engineering, Management, \& Applied Sciences \& Technologies, 2(1). Retrieved from http://TuEngr.com/V02/083-091.pdf 
LeBude, A. V., Blazich, F. A., Walker, L. C., \& Robinson, S. M. (2008). Seed germination of two populations of Rhododendron vaseyi: Influence of light and temperature. J. Environ. Hort., 26, 217-22

Lee, S., Cheng, H., King, K. E., Wang, W., He, Y., Hussain, A., \& Peng, J. (2002). Gibberellin regulates Arabidopsis seed germination via RGL2, a GAI/RGA-like gene whose expression is up-regulated following imbibition. Genes \& development, 16(5), 646-658. http://dx.doi.org/10.1101/gad.969002

Murdoch, A. J., \& Ellis, R. H. (2000). Dormancy, viability and longevity. Seeds: the ecology of regeneration in plant communities, 2, 183-214.

Oh, E., Yamaguchi, S., Kamiya, Y., Bae, G., Chung, W. I., \& Choi, G. (2006). Light activates the degradation of PIL5 protein to promote seed germination through gibberellin in Arabidopsis. Plant $J$. http://dx.doi.org/ 10.1111/j.1365-313X.2006.02773.x

Oliveira, V. M. de, Forni-Martins, E. R., Magalhães, P. M., \& Alves, M. N. (2004). Chromosomal and morphological studies of diploid and polyploid cytotypes of Stevia rebaudiana (Bertoni) Bertoni (Eupatorieae, Asteraceae). Genetics and Molecular Biology, 27(2), 215-222. http://dx.doi.org/10.1590/S1415-475720040 00200015

Runkle, E. S., \& Heins, R. D. (2001). Specific functions of red, far red, and blue light in flowering and stem extension of long-day plants. Journal of the American society for horticultural science, 126(3), 275-282.

Sakaguchi, M., \& Kan, T. (1992). Japanese researches on Stevia rebaudiana Bertoni and 335 stevioside. Ci, Cult. 34, 235-248.

Seo, M., Hanada, A., Kuwahara, A., Endo, A., Okamoto, M., Yamauchi, Y., ... \& Nambara, E. (2006). Regulation of hormone metabolism in Arabidopsis seeds: phytochrome regulation of abscisic acid metabolism and abscisic acid regulation of gibberellin metabolism. The Plant Journal, 48(3), 354-366. http://dx.doi.org/10.1111/j.1365-313X.2006.02881.x

Shyam, S. S., \& David, N. S. (1975). Effect of light on seed germination and seedling growth of Merremia species. Folia Geobotanica \& Phytotaxonomia, 10(3), 265-269.

Soejarto, D. D., Compadre, C. M., Medon, P. J., Kamath, S. K., \& Kinghorn, A. D. (1983). Potential sweetening agents of plant origin. II. Field search for sweet-tasting Stevia species. Econ. Bot., 37, 71-79. http://dx.doi.org/10.1007/BF02859308

Soejarto, D. D., Kinghorn, A. D., \& Farnsworth, N. R. (1982). Potential sweetening agents of plant origin. III.Organoleptic evaluation of stevia leaf herbarium samples for sweetness. J. Nat. Prod., 45, 590-599.

Strauss, S. (1995). The perfect sweetener? Technol. Rev, 98, 18-20.

Traveset, A. (1998). Effect of seed passage through vertebrate frugivores' guts on germination: a review. Perspectives in Plant ecology, evolution and systematics, 1(2), 151-190. http://dx.doi.org/10.1078/1433-83 19-00057

Walker, L. C., LeBude, A. V., Blazich, F. A., \& Conner, J. E. (2006). Seed germination of pinkshell azalea (Rhododendron vaseyi) as influenced by light and temperature. Proc. SNA Res. Conf. (51st Annu. Rpt. p. 370-373).

Whitaker, J. (1995). Sweet justice: FDA relents on stevia. Human Events, 51, 11.

\section{Copyrights}

Copyright for this article is retained by the author(s), with first publication rights granted to the journal.

This is an open-access article distributed under the terms and conditions of the Creative Commons Attribution license (http://creativecommons.org/licenses/by/3.0/). 